\title{
OWNER-INTRUDER CONTESTS WITH INFORMATION ASYMMETRY
}

\author{
Jay Bisen $^{1}$, Faheem Farooq ${ }^{1}$, Manaeil Hasan ${ }^{1}$, Akhil Patel $^{2}$, \\ JAN RYCHTÁr ${ }^{3, *}$ AND DEWEY TAYLOR ${ }^{3}$
}

\begin{abstract}
We consider kleptoparasitic interactions between two individuals - the Owner and the Intruder - and model the situation as a sequential game in an extensive form. The Owner is in possession of a resource when another individual, the Intruder, comes along and may try to steal it. If the Intruder makes such a stealing attempt, the Owner has to decide whether to defend the resource; if the Owner defends, the Intruder can withdraw or continue with the stealing attempt. The individuals may value the resource differently and we distinguish three information cases: (a) both individuals know resource values to both of them, (b) individuals know only their own valuation, (c) individuals do not know the value at all. We solve the game in all three cases. We identify scenarios when it is beneficial for the individuals to know as much information as possible. We also identify several scenarios where knowing less seems better as well as show that an individual may not benefit from their opponent knowing less. Finally, we consider the same kind of interactions but without the option for the Intruder to withdraw. We find that, surprisingly, the Intruder typically fares better in that case.
\end{abstract}

Mathematics Subject Classification. 91A05, 91A40, 91A22.

Received February 3, 2020. Accepted January 16, 2021.

\section{INTRODUCTION}

In nature, kleptoparasitism, the act of stealing and fighting over resources, is common among birds [46, 47, 49]; but it occurs across many types of species such as insects [32], fish [27] and mammals [34]. There are many different behaviors involved in kleptoparasitic interactions. Sometimes individuals will defend and fight for the resource and sometimes the resource is simply forfeited without any conflict [30].

There are many models of kleptoparasitic interactions with varying degree of complexity, see for example $[4,6,8,9,23]$. Many recent models contain a high degree of detail and realism, see for example [24-26, 51, 52]. An Owner-Intruder game is a common way to model kleptoaparasitic interactions; it can account for many different situations and assumptions while yielding clear and testable predictions [1-3, 15, 17, 19, 20, 22, 39], see also [44] or [29] for recent reviews.

Keywords and phrases: Game theory, kleptoparasitism, resource valuation, information asymmetry.

1 Department of Biology, Virginia Commonwealth University, Richmond, VA 23284-2012, USA.

2 Department of Biomedical Engineering, Virginia Commonwealth University, Richmond, VA 23284-3068, USA.

3 Department of Mathematics and Applied Mathematics, Virginia Commonwealth University, Richmond, VA 23284-2014, USA.

* Corresponding author: rychtarj@vcu.edu 
The value of the resource has a substantial influence on the interaction [7, 10, 13, 48]. Determining the resource value is not an easy task. For example, the value of a territory depends on factors such as access to food [36], mating opportunities [45], refuge from predators [16] and many others. The subjective value of the resource may also depend on the individual's Resource Holding Potential (RHP), [40]. When the individuals are competing for resources to survive, the desperate individuals value the resource more than those that are well-fed; this is seen in the case of Olrog's Gull Larus atlanticus [18]. On the other hand, when the individuals compete for access to mates, the stronger individuals may value the resource more. This is seen in the case of the ant colonies with multiple queens $[43,53]$.

When there is a difference in resource valuation, several cases have to be distinguished. First, individuals may know the resource value to themselves and also to the opponent. For example, the male ray-finned fish sand goby, Pomatoschistus minutus, compete for nest sites; the value of the site can be quickly assessed by its size and so can the opponent's RHP [35]. A similar situation was observed in male paper wasps, Polistes fuscatus, fighting over territory [42]. Second, individuals may know how much they value the resource themselves, but do not know the value to the opponent. This is the case when RHP cannot be easily assessed, for example in the contests between Mozambique mouthbrooder, Oreochromis mossambicus, [50], or damselflies, Calopteryx maculata, [37]; see [38] for more details. Finally, individuals may not know the resource value for themselves or for their opponent. Such scenarios are likely not common, but may theoretically still happen among animals like the great tit, Parus major, [33] when the contest happens between the intruder and a new territory owner that does not yet know the true value of the territory.

In this paper, we consider a scenario where one individual, the Owner, has a valuable resource that another individual, the Intruder, may want to steal. In Section 2 we set up the Owner-Intruder game as an extension of the game considered in [12]. In Section 3 we solve the game for all three information cases. In Section 4 we compare the outcomes between the cases to see the effect of extra information. In Section 5 we investigate the differences in outcomes between [12] and our extended model. We conclude our paper by a discussion in Section 6.

\section{MODEL}

We model the conflict between the Owner and the Intruder as a sequential game in extensive form. Our model extends the game studied in [12] by one round (in which the Intruder can withdraw from the conflict or continue with the stealing attempt by attacking the Owner), see Figure 1. The notation is summarized in Table 1.

The Owner is in possession of a resource when another individual, the Intruder comes along and may try to steal it. If the Intruder makes such a stealing attempt, the Owner has two options: (O1) it can either flee the area which will result in the Intruder taking over the resource, or $(\mathrm{O} 2)$ it can stay and defend the resource. In the latter case, the Intruder then has to reevaluate and choose one of the two options: (I1) to withdraw from the conflict and flee the area before the conflict escalates, or (I2) to continue with the stealing attempt and attack the Owner. If the Intruder leaves, the Owner keeps the resource and no individual pays any cost. If the Intruder attacks, it results in a fight. The Owner wins the fight with probability $a$; the Intruder wins with probability $1-a$. The winner will gain the resource, and the loser will gain nothing. Both individuals will have to pay a cost $c$ for the fight.

The same resource may have a different value to different individuals. Let $V_{O}$ denote the value of the resource to the Owner and $V_{I}$ the value of the same resource to the Intruder. We will distinguish three cases: (1) the full information case when the Owner and the Intruder both know the values of $V_{O}$ and $V_{I},(2)$ the partial information case when the Owner knows $V_{O}$, the Intruder knows $V_{I}$, but neither individual knows the resource value for the opponent, and finally (3) the no information case when neither individual knows $V_{O}$ nor $V_{I}$ (but they both know the expected values $E\left[V_{O}\right]$ and $\left.E\left[V_{I}\right]\right)$.

Throughout this paper, we will assume that $V_{O}$ and $V_{I}$ are independent identically distributed random variables; in particular $E\left[V_{O}\right]=E\left[V_{I}\right]$. For illustrative and comparison purposes, we assume $V_{O}$ and $V_{I}$ are uniformly distributed on $[0,4]$ as in $[12]$. 

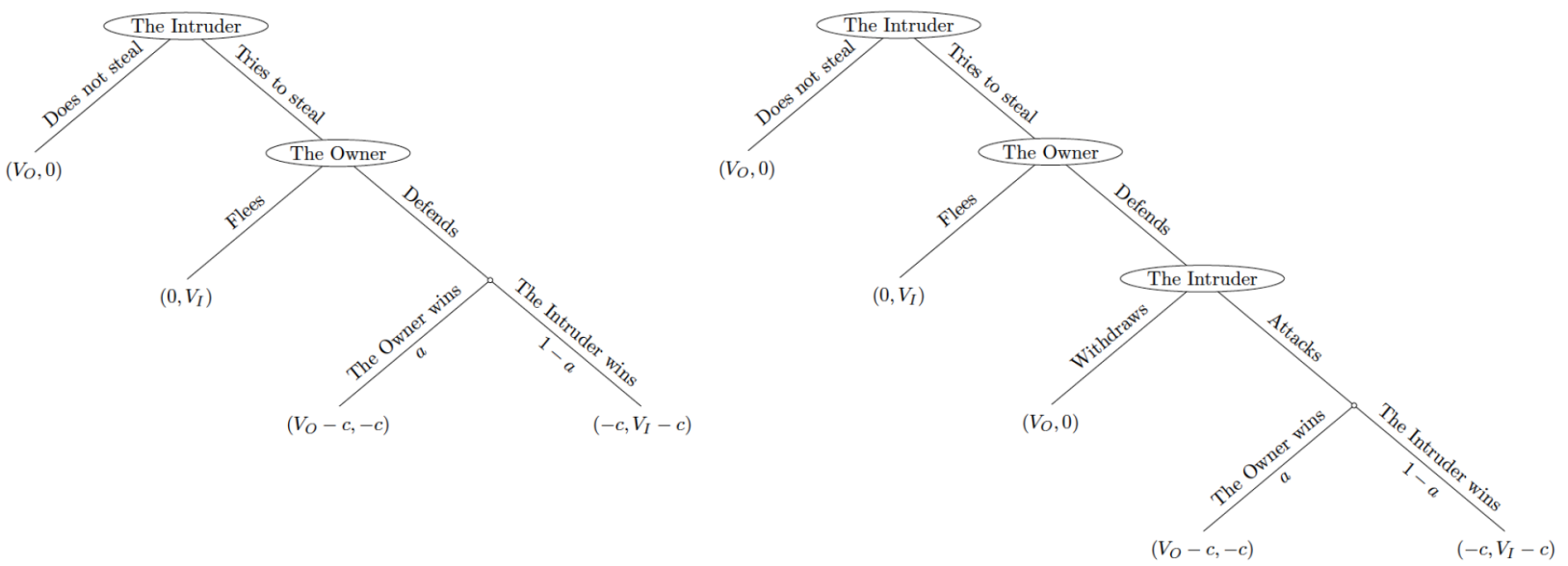

Figure 1. Scheme and payoffs of the Owner-Intruder game. We extend of the game considered in [12] (left). The version considered in our paper (right) adds one more round in which the Intruder can either withdraw before the conflict escalates or continue the stealing attempt. In [12], once the Intruder decided to steal, it had to continue with the attempt once the Owner decided to defend.

TABLE 1. Summary of the notation.

\begin{tabular}{ll}
\hline Notation & Meaning \\
\hline$V_{I}$ & Value of the resource for the Intruder; a random variable with a given distribution \\
$V_{O}$ & Value of the resource for the Owner; a random variable; i.i.d. with $V_{I}$ \\
$E[V]$ & Expected value of the resource for the Owner or the Intruder \\
$c$ & Cost of the fight; $c>0$ \\
$a$ & Probability of the Owner winning the fight; $a \in(0,1)$ \\
$\pi_{I}$ & Probability that the Intruder will attack given the Owner defends; $\pi_{I}=\operatorname{Prob}\left(\frac{c}{1-a}<V_{I}\right)$ \\
$\pi_{O}$ & $\begin{array}{l}\text { Probability that the Owner will defend given the Intruder tries to steal; this relevant only in } \\
\text { the scenario from }[14] \text { without the Intruder's option to withdraw; } \pi_{O}=\operatorname{Prob}\left(\frac{c}{a}<V_{O}\right)\end{array}$ \\
$P_{O}^{\text {Info case }}$ & Payoff to the Owner in the given information case \\
$P_{I}^{\text {Info case }}$ & Payoff to the Intruder in the given information case \\
\hline
\end{tabular}

\section{AnALYsis}

We note that, in the first round, the Intruder should always decide to try to steal since it does not gain anything by not stealing. It can always withdraw in the next round. Consequently, adding the extra round for the Intruder is equivalent to considering the model from [12] with the order of decisions reversed, i.e. the Owner deciding first whether to flee or defend, the Intruder deciding second whether to attack or flee. The fight will happen only of the Owner decided to defend and the Intruder decided to attack.

Consequently, the results from [12] can be readily adapted to the current game. The behavioral outcomes and corresponding payoffs are summarized in Table 2, see also Figure 2. It follows from Table 2 that the payoffs to the individuals depend on the relationship between the resource values $V_{O}$ and $V_{I}$ and the quantities $\frac{c}{a}$ and $\frac{c}{1-a}$. 
TABLE 2. Summary of behavioral outcomes and payoffs depending on the information case and conditions on $V_{I}$ and $V_{O}$. In all cases, the Intruder tries to steal first. We note that this table could be reconstructed directly from Table 13.1 in [12] and vice versa by the following substitutions: "The Owner" $\leftrightarrow$ "Scrounger", "The Intruder" $\leftrightarrow$ "Producer", " $V_{O} " \leftrightarrow$ " $\nu_{s}$ ", "V $V_{I} " \leftrightarrow$ " $\nu_{p} ", " a " \leftrightarrow " 1-a ", " \pi_{I} " \leftrightarrow$ " $\pi$ ".

\begin{tabular}{|c|c|c|c|c|c|c|c|}
\hline \multicolumn{2}{|c|}{ Behavior and payoffs } & \multicolumn{2}{|c|}{ Full information } & \multicolumn{2}{|c|}{ Partial information } & \multicolumn{2}{|c|}{ No information } \\
\hline The owner & The intruder & & & & & & \\
\hline $\begin{array}{c}\text { Defends } \\
V_{O}\end{array}$ & $\begin{array}{c}\text { Withdraws } \\
0\end{array}$ & $\frac{c}{1-a}>V_{I}$ & any $V_{O}$ & $\frac{c}{1-a}>V_{I}$ & $\frac{\pi_{I} c}{1-(1-a) \pi_{I}}<V_{O}$ & $\frac{c}{1-a}>E\left[V_{I}\right]$ & \\
\hline $\begin{array}{l}\text { Defends } \\
a V_{O}-c\end{array}$ & $\begin{array}{c}\text { Attacks } \\
(1-a) V_{I}-c\end{array}$ & $\frac{c}{1-a}<V_{I}$ & $\frac{c}{a}<V_{O}$ & $\frac{c}{1-a}<V_{I}$ & $\frac{\pi_{I} c}{1-(1-a) \pi_{I}}<V_{O}$ & $\frac{c}{1-a}<E\left[V_{I}\right]$ & $\frac{c}{a}<E\left[V_{O}\right]$ \\
\hline $\begin{array}{c}\text { Flees } \\
0\end{array}$ & $\begin{array}{c}\text { Takes over } \\
V_{I}\end{array}$ & $\frac{c}{1-a}<V_{I}$ & $\frac{c}{a}>V_{O}$ & any $V_{I}$ & $\frac{\pi_{I} c}{1-(1-a) \pi_{I}}>V_{O}$ & $\frac{c}{1-a}<E\left[V_{I}\right]$ & $\frac{c}{a}>E\left[V_{O}\right]$ \\
\hline
\end{tabular}

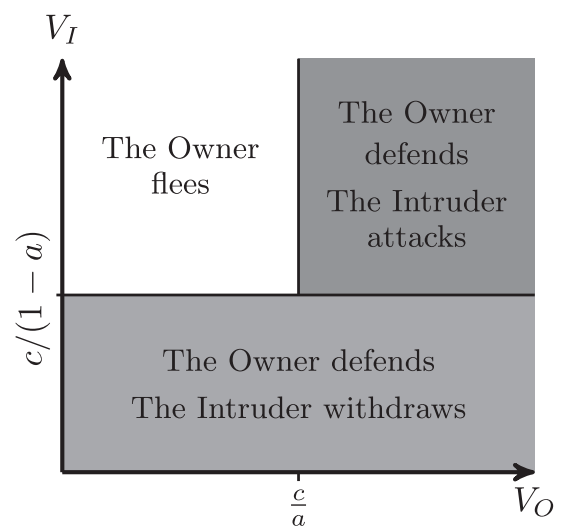

(A) Full information case

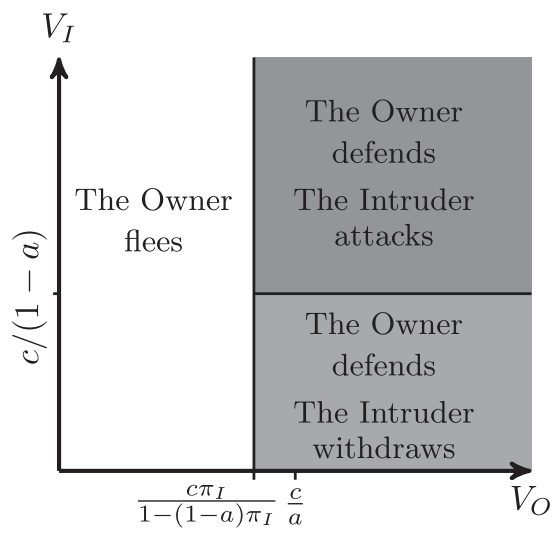

(B) Partial information case

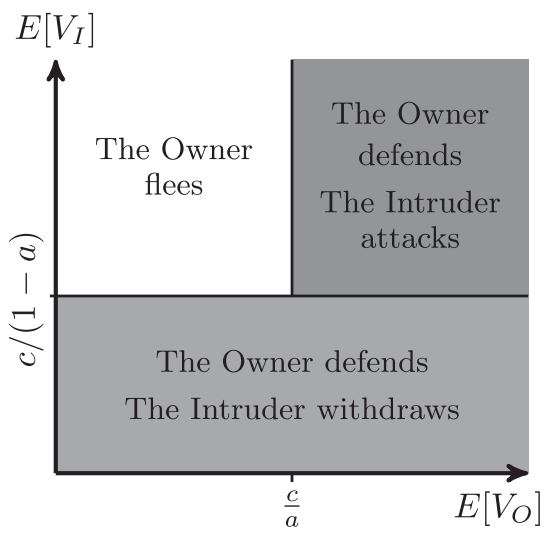

(c) No information case

Figure 2. Behavioral outcomes of the game for the different information cases. In all cases, the Intruder tries to steal first. The payoffs depend on the subsequent behavior of the Owner and the Intruder and are as follows: 1 ) when the Owner defends and the Intruder withdraws: $P_{O}=V_{O}$, $\left.P_{I}=0,2\right)$ when the Owner defends and the Intruder attacks: $P_{O}=a V_{O}-c, P_{I}=(1-a) V_{I}-c$, $3)$ when the Owner flees (and the Intruder takes the resource): $P_{O}=0, P_{I}=V_{I}$.

\section{Comparison Between different information CASES}

In this section we provide the comparison between the full, partial, and no information cases for the Owners and the Intruders. The proper analysis would follow and mimic the analysis done in [12]. The payoffs to the Owner (resp. the Intruder) in the full, partial, and no information case will be denoted $P_{O}^{F}, P_{O}^{P}, P_{O}^{N}$ (resp. $\left.P_{I}^{F}, P_{I}^{P}, P_{I}^{N}\right)$.

We note that $V_{O}$ and $V_{I}$ are random variables and the payoffs depend on $V_{O}$ and $V_{I}$. While we can (and often will) compare the payoffs for specific values of $V_{O}$ and $V_{I}$, we will also compare the mean values of the payoffs (as in Fig. 3). We will also explore the distribution of the payoff values in Figures 4 and 5.

Under all circumstances we have $P_{O}^{F} \geq P_{O}^{P}$ i.e. for the Owner, once it knows the value of $V_{O}$, it is always beneficial to know the value of $V_{I}$. 

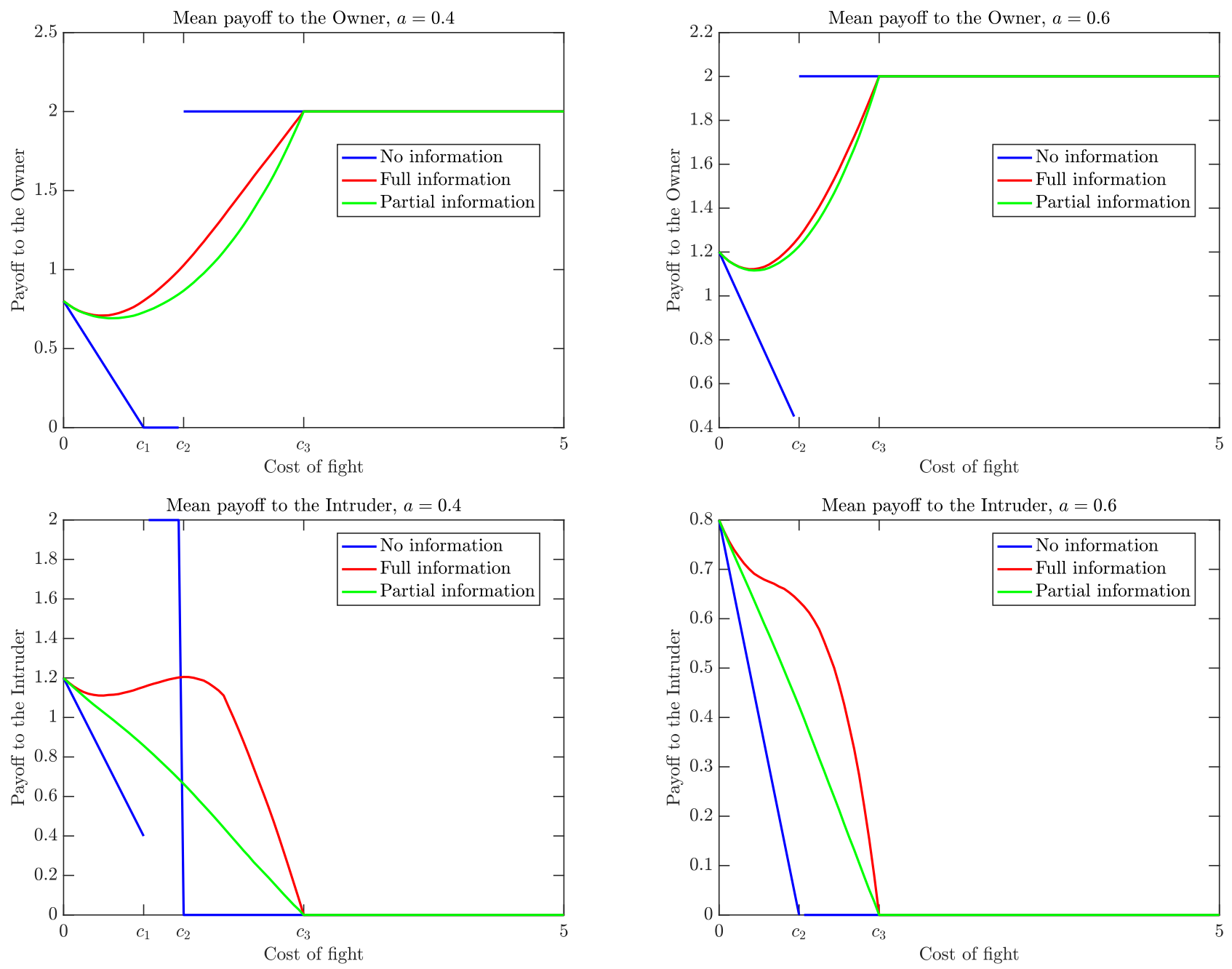

Figure 3. Mean payoffs to the Owner (top) and the Intruder (bottom) under different information cases. Here $c$ varies, $V_{O}$ and $V_{I}$ have the uniform distribution on [0,4] and $a=0.4$ (left) or $a=0.6$ (right). In these figures, $c_{1}=a E[V], c_{2}=(1-a) E[V], c_{3}=(1-a) \max [V]$.

The situation is different for the Intruder. Note that since the Intruder does not need to know the value of $V_{O}$ for its decision, the comparison between the full and partial information cases is effectively a comparison between a case when the Owner knows $V_{I}$ and when it does not know $V_{I}$ (while both the Owner and the Intruder know their own values).

If $V_{I}$ is small, it is better for the Intruder if the Owner does not know $V_{I}$. Indeed, in the partial information case, if the Owner does not know that $V_{I}$ is small (i.e. not worth it for the Intruder to fight), the Owner will give up when $V_{O}$ is small because it does not want to risk a fight. In the full information case, the Owner would know that the Intruder would not fight and thus the Owner would pretend to be ready to defend.

Using a similar argument, if $V_{I}$ is large, it is better for the Intruder if the Owner knows $V_{I}$. Indeed, in this case the Owner knows that the Intruder is going to fight and thus the Owner may decide to give up. In the partial information case, the Owner does not know $V_{I}$ and may thus defend which would force the Intruder to fight rather than get the resource for free. 

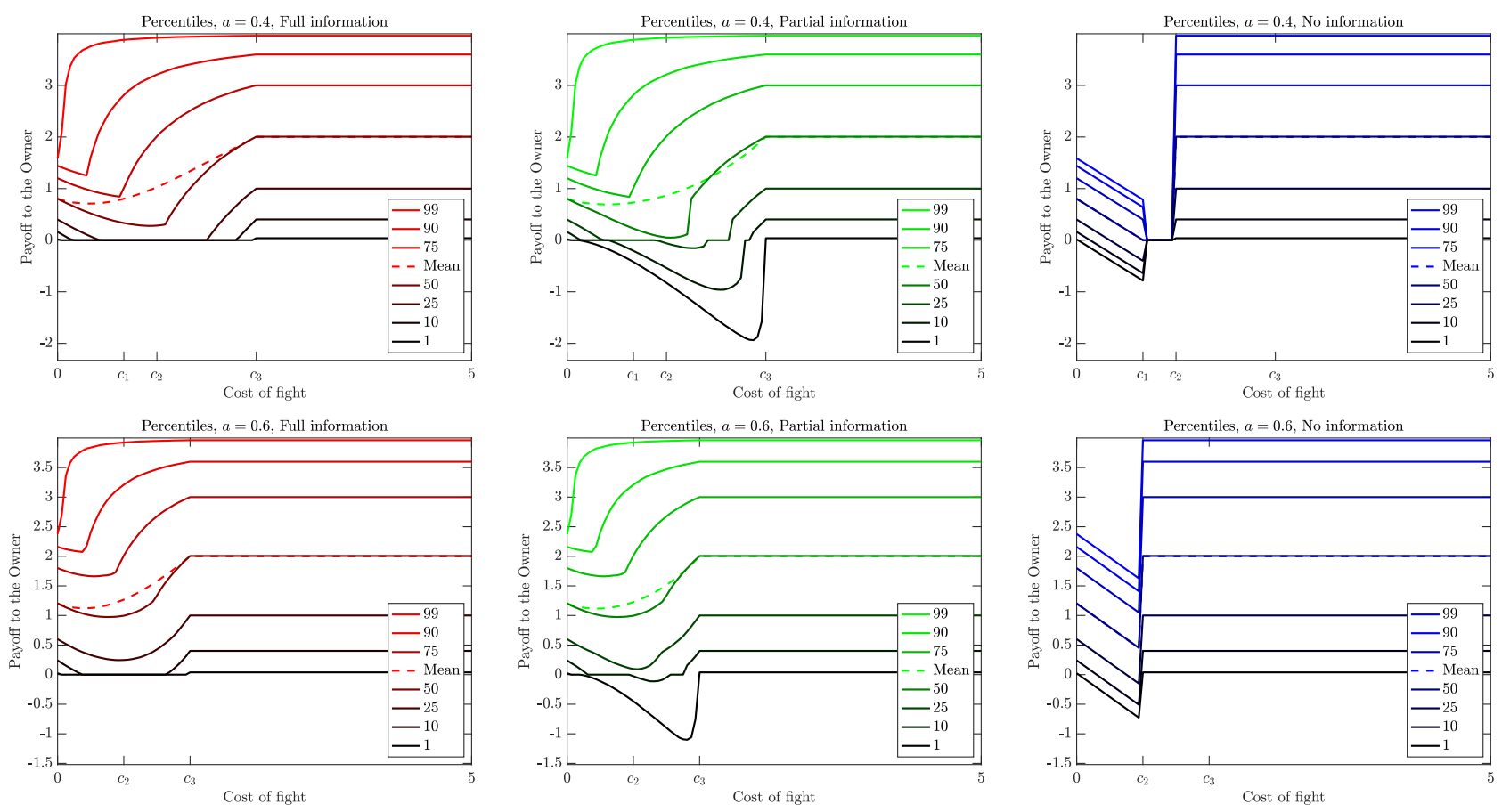

Figure 4. Percentiles of payoffs to the Owner under different information cases. Here $c$ varies, $a=0.4$ (top) and $a=0.6$ (bottom), $V_{O}$ and $V_{I}$ are drawn from the uniform distribution on $[0,4]$. All three information cases are shown: full information (left), partial information (center) and no information (right). In these figures, $c_{1}=a E[V], c_{2}=(1-a) E[V], c_{3}=(1-a) \max [V]$.

Now we will compare against no information cases. For the Owner, the no information case is best when the cost of the fight is relatively high, specifically when $c>(1-a) E\left[V_{I}\right]$. In this case, the Intruder is not going to risk the fight. It is still beneficial for the Intruder to bluff and try to steal. However, the Owner can call the bluff and pretend to be ready to defend the resource that may not be beneficial to defend in a real fight, forcing the Intruder to withdraw before the conflict escalates. However, when the cost of the fight is low, the no information case is not beneficial for the Owner.

For the Intruder, the no information case is best only when $a<0.5$ and only when the fight costs are intermediate. Specifically, when $a E\left[V_{O}\right]<c<(1-a) E\left[V_{I}\right]$, the cost is high enough for the Owner not to fight but low enough for the Intruder to fight if needed. For other fight costs, other information cases are better for the Intruder.

For all three information cases, the mean payoffs to the Owner and the Intruder are shown in Figure 3. The distribution of the payoffs are demonstrated in Figure 4 for the Owner and in Figure 5 for the Intruder. We note that all payoffs are non-negative in the full information case. The Owner may have a negative payoff in the partial information case and the no information case (although the mean payoffs are both non-negative). The Intruder has non-negative payoffs in the partial information case and can have negative payoffs (but with non-negative mean) in the no information case.

\section{Comparison to the game Without the option to WithdraW}

In this section, we compare our results with the results of [12] where the Intruder did not have the option to withdraw before the conflict escalates. Intuitively, one would think that adding this option will only be beneficial 

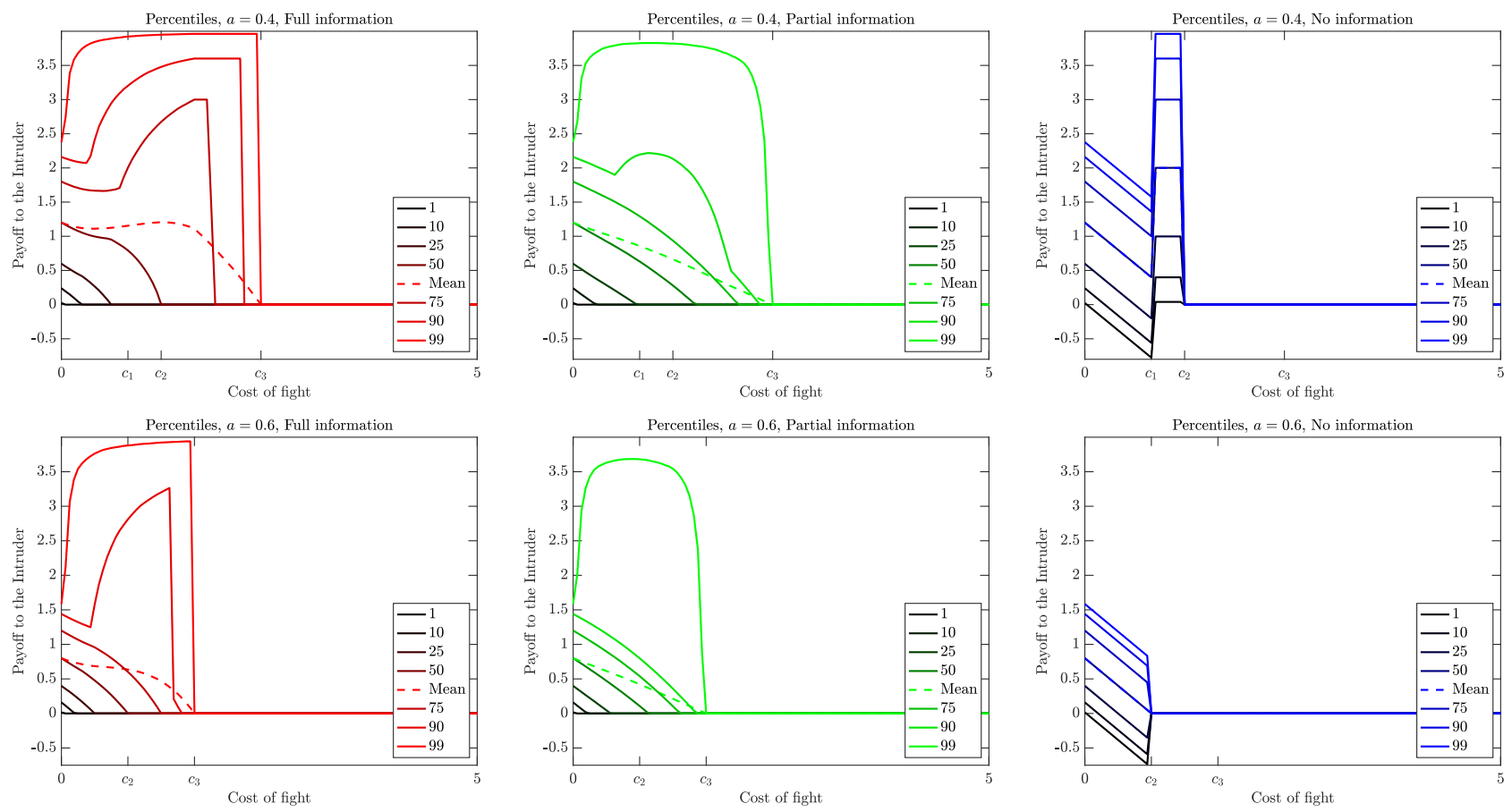

Figure 5. Percentiles of payoffs to the Intruder under different information cases. Here $c$ varies, $a=0.4$ (top) and $a=0.6$ (bottom), $V_{O}$ and $V_{I}$ are drawn from the uniform distribution on $[0,4]$. All three information cases are shown: full information (left), partial information (center) and no information (right). In these figures, $c_{1}=a E[V], c_{2}=(1-a) E[V], c_{3}=(1-a) \max [V]$.

to the Intruder, but we will see that it is not always the case. The results of [12], in our current terminology and notation, are summarized in Figure 6.

Let us start by comparing the outcomes in the full information case. When $V_{O}>\frac{c}{a}$ or $V_{I}>\frac{c}{1-a}$, the extra round does not matter. The individuals will take comparable actions and receive the same payoff with or without option to withdraw. However, when $V_{O}<\frac{c}{a}$ and $V_{I}<\frac{c}{1-a}$, the extra round matters. When the Intruder has the option to withdraw, the Owners defend and the Intruders subsequently withdraw. Consequently, $P_{O}=V_{O}$ and $P_{I}=0$. However, without the extra option, the Intruders try to steal and the Owners flee, i.e. $P_{O}=0$ and $P_{I}=V_{I}$. The addition of the Intruder's option to withdraw from the conflict benefits the Owner, not the Intruder.

The situation in the no information case is similar to the full information case. Specifically, when $E\left[V_{O}\right]>\frac{c}{a}$ or $E\left[V_{I}\right]>\frac{c}{1-a}$, the extra round does not matter. The individuals will do comparable actions and receive the same payoff regardless whether the Intruder can or cannot withdraw from the conflict. However, when $E\left[V_{O}\right]<\frac{c}{a}$ or $E\left[V_{I}\right]<\frac{c}{1-a}$ the extra option matters. With this option, the Owner receives the full resource value while the Intruder individual gets 0 . Without this option, the Intruder gets the full value while the Owner gets 0 . In summary, for the no information case, the addition of the Intruder's option to withdraw from the conflict benefits the Owner, not the Intruder.

The situation is more complex in the partial information case, see Figure 7. There are four regions of parameter values where extra option will matter and we discuss the regions below.

Region I: Here $V_{O}<\frac{c \pi_{I}}{1-(1-a) \pi_{I}}$ and $V_{I}<\frac{c \pi_{O}}{1-a \pi_{O}}$. If the Intruder can withdraw, the Owner flees and receives $P_{O}=0$ (and the Intruder receives $P_{I}=V_{I}$ ). However, if the Intruder cannot withdraw, the Intruder does not try to steal and receives $P_{I}=0$, while the Owner receives $P_{O}=V_{O}$. In this region, the extra option benefits 


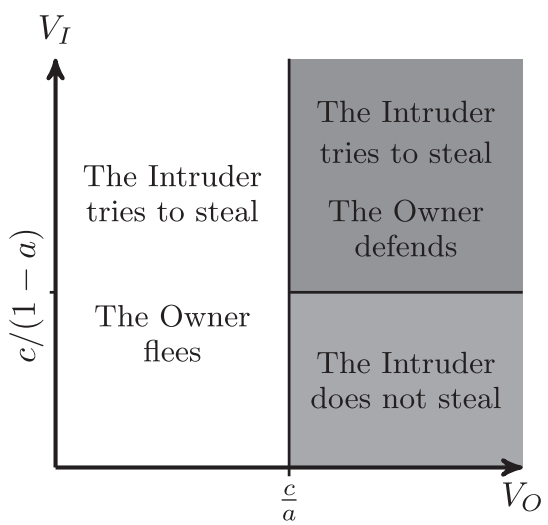

(A) Full information case

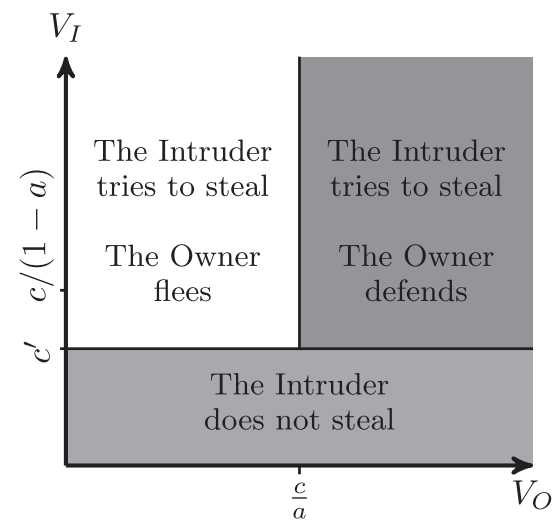

(B) Partial information case

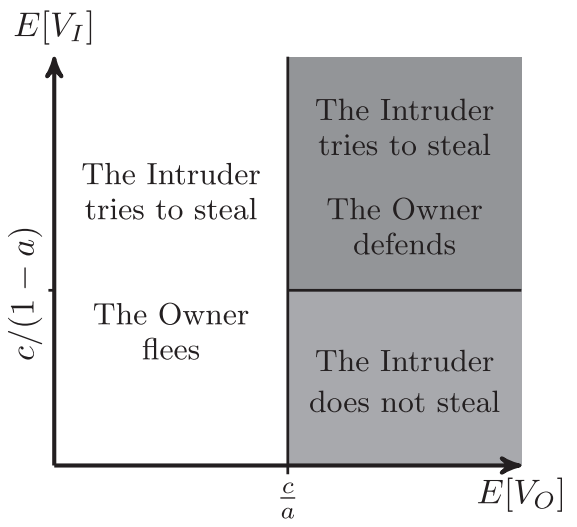

(c) No information case

FiguRE 6. Behavioral outcomes of the game for the different information cases in the game from [12] where the Intruder cannot withdraw from the conflict. The payoffs depend on the behavior of the Intruder and the Owner and are as follows: 1$)$ when the Intruder does not steal: $\left.P_{O}=V_{O}, P_{I}=0,2\right)$ when the Intruder tries to steal and the Owner defends: $P_{O}=a V_{O}-c$, $\left.P_{I}=(1-a) V_{I}-c, 3\right)$ when the Intruder tries to steal and the Owner flees: $P_{O}=0, P_{I}=V_{I}$. Here, $c^{\prime}=\frac{c \pi_{O}}{1-a \pi_{O}}$ where $\pi_{O}=\operatorname{Prob}\left(\frac{c}{a}<V_{O}\right)$.

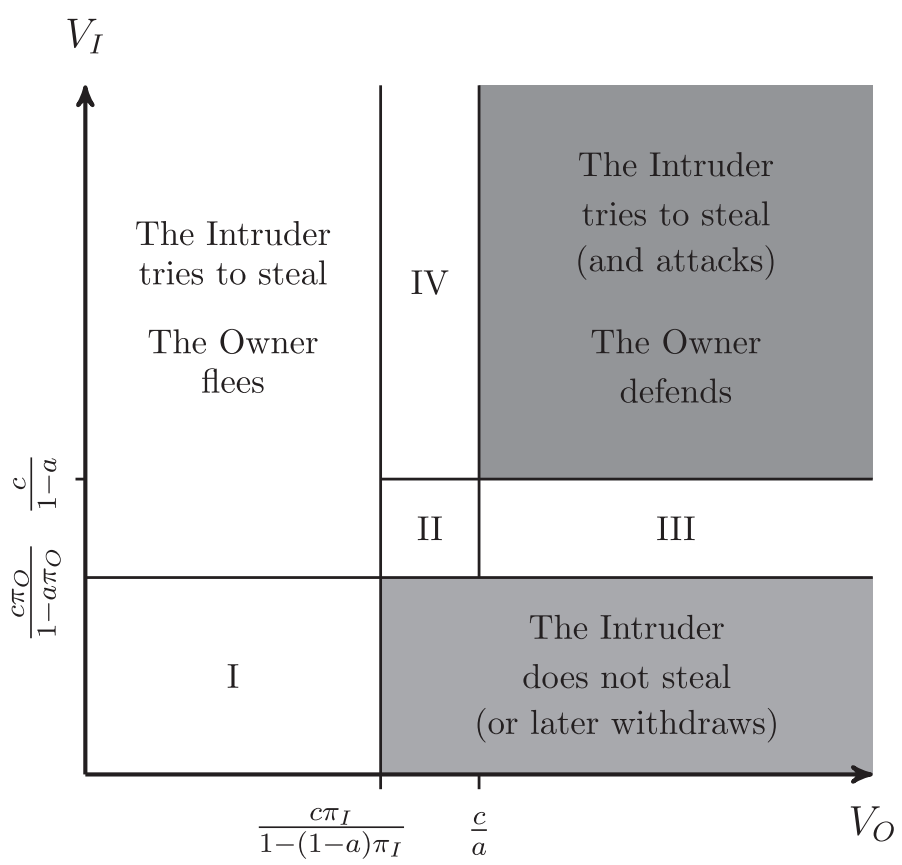

Figure 7. Partial information case - the effect of the extra option to withdraw before the conflict escalates. When the action is described, the extra option does not matter. In the regions labeled I, II, III, and IV, the extra option matters and the actions and payoffs are described in the text.

the Intruder. With this option, the Owner does not want to risk the fight and flees. Without this option, the Intruder does not want to risk the fight and thus does not even attempt to steal. 
Region II: Here $\frac{c \pi_{I}}{1-(1-a) \pi_{I}}<V_{O}<\frac{c}{a}$ and $\frac{c \pi_{O}}{1-a \pi_{O}}<V_{I}<\frac{c}{1-a}$. If the Intruder can withdraw, the Owner defends and the Intruder subsequently withdraws. Consequently, $P_{O}=V_{O}$ and $P_{I}=0$. However, when the Intruder cannot withdraw, they try to steal and the Owners then flee, i.e. $P_{I}=V_{I}$ and $P_{O}=0$. So, in this region, the addition of the Intruder's option to withdraw from the conflict benefits the Owner, not the Intruder. Without the option, the Intruder can bluff and pretend to be ready to fight. With the extra option, the Owner can call the bluff and pretend to be ready to defend as well, forcing the Intruder to give up.

Region III: Here $\frac{c}{a}<V_{O}$ and $\frac{c \pi_{O}}{1-a \pi_{O}}<V_{I}<\frac{c}{1-a}$. If the Intruder has the option to withdraw, the Owner defends while the Intruder subsequently withdraws. Consequently, $P_{O}=V_{O}$ and $P_{I}=0$. However, without the option, the Intruder tries to steal and the Owner then defends, i.e. $P_{I}=(1-a) V_{I}-c<0$ and $P_{O}=a V_{O}-c>0$ (but $P_{O}<V_{O}$ ). In this case, both individual benefits from the extra option.

Region IV: Here $\frac{c \pi_{I}}{1-(1-a) \pi_{I}}<V_{O}<\frac{c}{a}$ and $\frac{c}{1-a}<V_{I}$. If the Intruder can withdraw, the Owner defends and the Intruder then attacks. Consequently, $P_{O}=a V_{O}-c<0$ and $P_{I}=(1-a) V_{I}-c<V_{I}$. If the Intruder cannot withdraw, the intruder tries to steal and the Owner then leaves. Consequently, $P_{I}=V_{I}$ and $P_{O}=0$. In this region, the addition of the Intruder's option to withdraw from the conflict benefits the Owner, not the Intruder.

\section{Conclusions And discussion}

In this paper, we investigated the effect of information on behavior during interactions between an Owner of a valuable resource and an Intruder. We distinguished three information cases - (1) the full information case when the individuals know the resource values for themselves as well as their opponents, (2) the partial information case when the individuals know the resource values for themselves but not for their opponents, and (3) the no information case when the individuals do not know the resource values at all. For each information case, we determined when it is optimal for the Owner to defend their resource and for the Intruder to fight for it.

We observed that the actual contests occur only when the cost of the fight is relatively low compared to the resource value. This is in an agreement with previous experiments. For example, fights among group living pholcid spiders, Holocnemus pluche, are more common over larger (more valuable) prey, without any observable increase in the fight cost [31].

Not surprisingly, under most circumstances, it is beneficial for the individual to know more rather than to know less. In particular, Owner's payoff in the full information case is larger than in the partial information case. Such a phenomenon was also observed before. For example, in [21] the authors used a sequential assessment game to model a situation where the owner of the resource knows its subjective value while the individual attempting to steal it may or may not know its value. Both individuals were making choices to fight or to flee. It was shown that the chances of owner's victory increased with the increasing value of the resource. This result was attributed to the Owner having an advantage provided by the extra knowledge.

However, when the average value of the resource is smaller than the expected cost of fighting for the Intruder, the no information case is best for the Owner (because the Intruder will flee and not fight). Similarly, when the average value of the resource is small enough for the Owner to fight yet large enough that the Intruder is willing to fight, then the no information case is best for the Intruder. In both cases though, the advantage seems to come from the opponent knowing less. A more detailed model accounting for all sixteen possibilities (each player knowing or not knowing the resource value for oneself and knowing or not knowing the resource value for the opponent), is needed to make the proper distinction. For example, the males of orb-weaving spider Metellina mengei fight over females [5] and the Owner may know the value of the reward to itself, but the Intruder does not; such a situation was not captured by our current model.

We saw that increasing the opponent's knowledge may be helpful in some instances and detrimental in others. Specifically, contestants prefer opponents to know that they are willing to fight. They also prefer to hide that they are not going to fight when challenged. This may be the case of bald eagles contesting over a prey item, who often assess the size and hunger level of their opponents and attack those most likely to retreat [28]. In general, the fact that an individual may benefit from an opponent's knowledge may be a factor behind the evolution of signalling, see for example [41]. 
We also studied the effect of the extra round during which the Intruder can withdraw before the contest escalates. We saw that, surprisingly, this round had an adverse effect on the Intruder's payoff in the full and no information cases when the fight costs are high. Without the possibility of a withdrawal, the Intruder bluffs by showing a willingness to engage in a fight. Should the fight really happen, it would be too costly. However, the fight is costly also for the Owner who thus flees and no fight will take a place. Yet, when the Intruder can withdraw, the Owner can call the bluff and display its willingness to defend, effectively forcing the Intruder to give up and withdraw. When the fight cost is not so high, the extra round has no effect on the interaction. The situation is more complex in the partial information case. When the cost is high, the extra round helps the Intruder. The Owner may need to give up because it does not want to risk that the cost is not high enough for the Intruder to withdraw. When the cost is intermediate, the extra round hurts the Intruder. We note that it would be interesting to test these predictions.

Also, we note that [11] considered a full information version of a conflict between Owner and Intruder in which each could decide multiple times whether or not to stay in the contest. Each animal had to pay a cost every time they decided to stay. [11] concluded that despite the inherent complexity, the resulting game often leads to the case where both animals fight to the fullest extent or where one concedes immediately. It would be interesting to see how and whether the conclusion changes in the partial information case.

There is a natural extensions of our model that should be considered in the future. We assumed no correlation between the resource values to individual contestants. This may not always be the case. For example, the value of a food item correlates with its calorie content, the value of a territory correlates with its size etc. So while values for the Owner and the Intruder may still be different, they are likely to be correlated as well.

Acknowledgements. J.B., F.F., M.H., and A.P. worked on this manuscript as part of the course MATH/BIOL $380-$ Introduction to mathematical biology. They acknowledge the help and support of their classmates. The authors would also like to thank the anonymous reviewers whose comments and feedback helped to improve the manuscript.

\section{REFERENCES}

[1] K. Argasinski and M. Broom, The nest site lottery: How selectively neutral density dependent growth suppression induces frequency dependent selection. Theor. Popul. Biol. 90 (2013) 82-90.

[2] K. Argasinski and R. Rudnicki, Nest site lottery revisited: Towards a mechanistic model of population growth suppressed by the availability of nest sites. J. Theoret. Biol. 420 (2017) 279-289.

[3] K. Argasinski and R. Rudnicki, From nest site lottery to host lottery: continuous model of growth suppression driven by the availability of nest sites for newborns or hosts for parasites and its impact on the selection of life history strategies. Theory Biosci. 130 (2020) 171-188.

[4] H. Barker, M. Broom and J. Rychtář, A game theoretic model of kleptoparasitism with strategic arrivals and departures of beetles at dung pats. J. Theor. Biol. 300 (2012) 292-298.

[5] A. Bridge, R. Elwood and J. Dick, Imperfect assessment and limited information preclude optimal strategies in male-male fights in the orb-weaving spider Metellina mengei. Proc. Royal Soc. London Ser. B 267 (2000) 273-279.

[6] M. Broom, M. Crowe, M. Fitzgerald and J. Rychtář, The stochastic modelling of kleptoparasitism using a Markov process. J. Theor. Biol. 264 (2010) 266-272.

[7] M. Broom, M. Johanis and J. Rychtár̆, The effect of fight cost structure on fighting behaviour involving simultaneous decisions and variable investment levels. J. Math. Biol. 76 (2018) 457-482.

[8] M. Broom, R. Luther, G. Ruxton and J. Rychtář, A game-theoretic model of kleptoparasitic behavior in polymorphic populations. J. Theor. Biol. 255 (2008) 81-91.

[9] M. Broom and J. Rychtář, A game theoretical model of kleptoparasitism with incomplete information. J. Math. Biol. 59 (2009) 631-649.

[10] M. Broom and J. Rychtár, A model of food stealing with asymmetric information. Ecological Complexity 26 (2016) 137-142.

[11] M. Broom and J. Rychtář, Evolutionary games with sequential decisions and dollar auctions. Dyn. Games Appl. 8 (2018) $211-231$.

[12] M. Broom, J. Rychtář and D. Sykes, The effect of information on payoff in kleptoparasitic interactions. In Topics from the 8th Annual UNCG Regional Mathematics and Statistics Conference. Springer (2013) 125-134.

[13] M. Broom, J. Rychtář and D. Sykes, Kleptoparasitic interactions under asymmetric resource valuation. Math. Model. Natur. Phenomena 9 (2014) 138-147.

[14] M. Broom and J. Rychtár̆, Game-theoretical models in biology. Chapman and Hall/CRC (2013).

[15] T. Caraco and L. Giraldea, Social foraging: producing and scrounging in a stochastic environment. J. Theor. Biol. 153 (1991) 559-583.

[16] G. Cowlishaw, Refuge use and predation risk in a desert baboon population. Animal Behav. 54 (1997) $241-253$. 
[17] R. Cressman and V. Křivan, Bimatrix games that include interaction times alter the evolutionary outcome: the Owner-Intruder game. J. Theor. Biol. 460 (2019) 262-273.

[18] J. Delhey, M. Carrete and M. Martinez, Diet and feeding behaviour of Olrog's gull Larus atlanticus in Bahia Blanca, Argentina. Ardea 89 (2001) 319-329.

[19] F. Dubois and L. Giraldeau, Fighting for resources: the economics of defense and appropriation. Ecology 86 (2005) 3-11.

[20] F. Dubois, L. Giraldeau and J. Grant, Resource defense in a group-foraging context. Behav. Ecol. 14 (2003) $2-9$.

[21] M. Enquist and O. Leimar, Evolution of fighting behaviour: the effect of variation in resource value. J. Theor. Biol. 127 (1987) $187-205$.

[22] I. Eshel and E. Sansone, Owner-intruder conflict, Grafen effect and self-assessment. The Bourgeois principle re-examined. J. Theor. Biol. 177 (1995) 341-356.

[23] N. Galanter, D. Silva Jr, J. Rowell and J. Rychtář, Resource competition amid overlapping territories: the territorial raider model applied to multi-group interactions. J. Theor. Biol. 412 (2017) 100-106.

[24] J. Garay, R. Cressman, T. Móri and T. Varga, The ess and replicator equation in matrix games under time constraints. J. Math. Biol. 76 (2018) 1951-1973.

[25] J. Garay, R. Cressman, F. Xu, M. Broom, V. Csiszár and T.F. Móri, When optimal foragers meet in a game theoretical conflict: a model of kleptoparasitism. J. Theor. Biol. 2020 (2020) 110306.

[26] J. Garay, V. Csiszár and T. Móri, Evolutionary stability for matrix games under time constraints. J. Theor. Biol. 415 (2017) $1-12$.

[27] M. Grimm and M. Klinge, Pike and some aspects of its dependence on vegetation. Pike: Biol. Exploitat. 1996 (1996) 125-156.

[28] A. Hansen, Fighting behavior in bald eagles: a test of game theory. Ecology 67 (1986) 787-797.

[29] M. Hinsch and J. Komdeur, What do territory owners defend against? Proc. Royal Soc. B: Biol. Sci. 284 (2017) 20162356.

[30] E. Iyengar, Kleptoparasitic interactions throughout the animal kingdom and a re-evaluation, based on participant mobility, of the conditions promoting the evolution of kleptoparasitism. Biol. J. Linnean Soc. 93 (2008) 745-762.

[31] E. Jakob, Contests over prey by group-living pholcids (Holocnemus pluchei). J. Arachnol. (1994) 39-45.

[32] R. Jeanne, Social biology of the neotropical wasp Mischocyttarus drewseni. Bull. Mus. Comp. Zool. Harvard Univ. 144 (1972) $63-150$.

[33] J. Krebs, Territorial defence in the great tit (Parus major): do residents always win? Behav. Ecol. Sociobiol. 11 (1982) $185-194$.

[34] H. Kruuk, The Spotted Hyena: A Study of Predation and Social Behavior. University of Chicago Press (1972).

[35] K. Lindström, The effect of resource holding potential, nest size and information about resource quality on the outcome of intruder-owner conflicts in the sand goby. Behav. Ecol. Sociobiol. 30 (1992) 53-58.

[36] C. Maher and D. Lott, Definitions of territoriality used in the study of variation in vertebrate spacing systems. Animal Behav. 49 (1995) 1581-1597.

[37] J. Marden and J. Waage, Escalated damselfly territorial contests are energetic wars of attrition. Animal Behav. 39 (1990) 954-959.

[38] M. Mesterton-Gibbons, J. Marden and L. Dugatkin, On wars of attrition without assessment. J. Theor. Biol. 181 (1996) $65-83$.

[39] M. Mesterton-Gibbons and T. Sherratt, Bourgeois versus anti-Bourgeois: a model of infinite regress. Animal Behav. 89 (2014) $171-183$.

[40] G. Parker, Assessment strategy and the evolution of fighting behaviour. J. Theor. Biol. 47 (1974) 223-243.

[41] R. Payne and M. Pagel, Escalation and time costs in displays of endurance. J. Theor. Biol. 183 (1996) 185-193.

[42] M. Polak, Large-size advantage and assessment of resource holding potential in male Polistes fuscatus (F.) (Hymenoptera: Vespidae). Animal Behav. 48 (1994) 1231-1234.

[43] H. Reeve, Queen-queen conflicts in polygynous societies: mutual tolerance and reproductive skew. In L. Keller, editor, Queen number and sociality in insects. Oxford University Press (1993) 45-85.

[44] T. Sherratt and M. Mesterton-Gibbons, The evolution of respect for property. J. Evol. Biol. 28 (2015) 1185-1202.

[45] B. Sinervo and C. Lively, The rock-scissors-paper game and the evolution of alternative male strategies. Nature 380 (1996) $240-243$.

[46] L. Spear, S. Howell, C. Oedekoven, D. Legay and J. Bried, Kleptoparasitism by brown skuas on albatrosses and giant-petrels in the Indian ocean. Auk 116 (1999) 545-548.

[47] W. Steele and P. Hockey, Factors influencing rate and success of intraspecific kleptoparasitism among kelp gulls (Larus dominicanus). The Auk 112 (1995) 847-859.

[48] D. Sykes and J. Rychtář, Optimal aggression in kleptoparasitic interactions. Involve 10 (2017) 735-747.

[49] P. Triplet, R. Stillman and J. Goss-Custard, Prey abundance and the strength of interference in a foraging shorebird. J. Animal Ecol. 68 (1999) 254-265.

[50] G. Turner and F. Huntingford, A problem for game theory analysis: assessment and intention in male mouthbrooder contests. Animal Behav. 34 (1986) 961-970.

[51] T. Varga, T. Móri and J. Garay, The ESS for evolutionary matrix games under time constraints and its relationship with the asymptotically stable rest point of the replicator dynamics. J. Math. Biol. 80 (2019) 743-774.

[52] T. Varga, J. Garay, J. Rychtář and M. Broom, A temporal model of territorial defence with antagonistic interactions. Theor. Popul. Biol. 134 (2020) 15-35.

[53] S. Vehrencamp, Optimal degree of skew in cooperative societies. Am Zool 23 (1983) 327-335. 